\title{
Cooperar para competir ou competir para cooperar?
}

\author{
Pedro Fernando Bendassolli
}

\begin{abstract}
O presente artigo discute a competição e cooperação no contexto organizacional tomando como base a concepção de trabalho e emprego dominantes hoje. O pressuposto do texto é de que o trabalho deve ser desvinculado de todas suas características essencialistas e que a cooperação entre as pessoas não se deve resumir ao trabalho, mas abraçar conceitos como os de dependência e solidariedade.
\end{abstract}

Palavras-chave: competição, cooperação, sentido do trabalho, pragmatismo.

$\mathrm{D}_{\mathrm{a}}^{\mathrm{e}}$ partida, o tema desta mesa-redonda lança um forte recado contraditório: por um lado, cooperação; por outro, a competição, ambos coexistindo na "vivência da classe trabalhadora". O primeiro membro desse par aparentemente contraditório lembra-nos do pronome comunal "nós", ao passo que o outro membro, a competição, lembra-nos do pronome de primeira pessoa, em princípio não-comunal, "eu". Tanto a "cooperação", quanto a "competição" têm um discurso próprio, discurso que equaciona cada uma dessas palavras num universo lingüístico específico, numa prática social específica. $O$ "discurso da cooperação" e o "discurso da competição", por assim dizer, não figuram num vácuo semântico. Por detrás de cada um deles há um conjunto de crenças e de regras que determinam o modo como são apresentados e o modo como instituem formas de vida, isto é, como ganham textura subjetiva e como passam a determinar comportamentos, estilos e práticas sociais.

O meu objetivo aqui é discutir o par "cooperação" e "competição" tendo como referência o trabalho. Contudo, não penso que o trabalho seja o setting exclusivo para esse tipo de discussão. Por isso acho interessante fazer uma rápida problematização sobre a importância que atribuímos ao trabalho num momento como este, momento em que prolifera o discurso do "fim do trabalho" - pelo menos de uma de suas designações clássicas, justamente aquela que tinha como lastro moral a chamada "ética protestante do trabalho".

Sendo assim, vou dividir minha fala em três pontos: (1) num primeiro ponto vou fazer um comentário sobre a importância do trabalho para a formação subjetiva, procurando mostrar que do posicionamento que tomemos quanto a esta questão depende nossa visão sobre a cooperação e a competição na "vivência da classe trabalhadora"; (2) num segundo ponto vou procurar fazer uma análise das principais características do corpo de crenças que sustentam o discurso da cooperação e da competição, tendo como referência uma análise do contexto do mercado de trabalho atual; (3) por fim, vou problematizar o modelo de subjetividade contida nos dois referidos discursos a partir de uma reconstrução das crenças

\footnotetext{
${ }^{1}$ Este artigo baseia-se na palestra apresentada na mesa-redonda Cooperação e Competição na Vivência da Classe Trabalhadora: para lembrar o dia do trabalho, organizada pelo Centro de Psicologia Aplicada ao Trabalho e pelo Serviço de Aconselhamento psicológico do Instituto de Psicologia da USP, em 21 de maio de 2001.

${ }^{2}$ Departamento de Psicologia Social e do Trabalho do Instituto de Psicologia da Universidade de São Paulo.
} 
que os sustentam, tentando mostrar outras alternativas éticas para o par "subjetividade/trabalho", "cooperação/competição" neste início de século.

\section{Ponto 1: Trabalho e subjetividade}

Começo com uma pergunta: qual é a importância do trabalho para a formação da subjetividade? Ora, essa pergunta pode pressupor, a priori, que há uma importância do trabalho para a formação da subjetividade. Por isso, é preciso uma pergunta anterior: como definir a subjetividade?

A partir de meu ponto de vista teórico, que se origina da filosofia neopragmática da linguagem, considero "subjetividade" como uma prática lingüística. Isto é, subjetividade é um efeito das linguagens que determinam suas regras de formação e reconhecimento privado e público. Ela é uma decorrência do uso de nossos vocabulários ou da maneira como aprendemos a ser sujeitos. "Vocabulário", tal como empregado aqui, não tem o sentido de mero glossário; pelo contrário, usado em seu sentido neopragmático, é sinônimo de prática lingüística, ou de jogos de linguagens, ou formas de vida. Segundo Wittgenstein, vocabulário tem o mesmo significado de linguagem. $O$ aspecto mais importante a destacar é que vocabulários diversos criam ou reproduzem subjetividades diversas.

Com essa definição, aquilo que postulamos como "importante para a formação da subjetividade" só será importante tendo em vista o sistema global de crenças adotado. Por exemplo, se lembrarmos da chamada "sociedade de classes", sobretudo quando essa vertente atingiu seu pico no século XIX, a posição do trabalho para a descrição da subjetividade tinha uma importância capital, mas não porque a "essência" da subjetividade fosse o trabalho, ou algo ligado a ele, mas porque um conjunto de crenças culturais descreviam como "verdadeira" a estreita ligação entre o trabalho e o próprio caráter pessoal.

A ética protestante do trabalho pode ser caracterizada como um conjunto de crenças que descreve a subjetividade a partir do ponto de vista do trabalho. Essa ética forma um vocabulário próprio, compondo roteiros, verdades, "essências" e "realidades" sobre o ser humano. Nessa ética, o humano "verdadeiro" era justamente o "humano no trabalho", aqui entendido como algo mais do que meramente uma ocupação funcional ou então um emprego. O "emprego" era apenas a predicação de uma categoria ontológica mais abrangente: o trabalho, a maneira como o "ser humano verdadeiro" encontrou para dominar a natureza e expressar sua "verdadeira subjetividade". Então, para esse discurso, o trabalho era uma categoria psicológico-antropológica chave e o ser humano era o que era tão somente por sua posição dentro de classes, redes, associações etc., que tinham como epicentro o trabalho.

Do ponto de vista, digamos, sociológico, a centralidade do trabalho era paralela a uma baixa oferta de referenciais subjetivos na cultura como um todo. Essa é uma hipótese. Além disso, as transformações por que vem passando o trabalho foram abalando sua posição central e essencial na definição da subjetividade. Hoje há muitos vocabulários alternativos para tal descrição e não há mais espaço para uma metanarrativa, como a metanarrativa que centralizava única e exclusivamente no trabalho a "essência" do humano. Olhando para o horizonte cultural de um modo amplo, sem centrar a atenção em particularidades, é possível vislumbrar centenas de vocabulários de descrição subjetiva.

Por um lado, isso enriquece a subjetividade, pois o "ser humano verdadeiro" deixa de ser encarado como tendo uma única faceta, justamente a faceta que o ligava ao trabalho. Outro aspecto é que hoje não há trabalho para todos, mas nem por isso haverá um 
"empobrecimento" subjetivo, desde que entendamos a subjetividade como algo que possa ser continuamente redescrito. Neste caso estou acentuando os efeitos, digamos, psicológicos da falta de trabalho. Fica de fora a análise das nefastas conseqüências econômicas dessa escassez de postos de trabalho, o que já serve para entristecer a comemoração "do dia do trabalho". Contudo, a partir do ponto de vista que assumo, o trabalho não é um referente privilegiado e único de descrição subjetiva, fato que serve para minimizar a pergunta com que comecei: "qual a importância do trabalho para a formação da subjetividade?" A importância do trabalho para tal formação vai depender da descrição que fizermos; não vai depender da "realidade em si", mas de nossas escolhas descritivas e da adequação dessas escolhas ao restante das crenças culturais sobre a matéria. É nesse contexto teórico que passo à análise da "cooperação" e da "competição" na vivência da classe trabalhadora.

\section{Ponto 2: O discurso da cooperação e da competição}

No moderno mercado de trabalho, o discurso da cooperação transfigurou-se no conceito de "trabalho em equipe". Trabalhar em grupo, defender objetivos a curto prazo levando-se em conta a diversidade de parceiros, tornou-se o jargão mais aceito do momento. A principal crença desse discurso consiste em fazer-nos crer que a autoridade é diluída em unidades de trabalho marcadas pela cooperação entre pessoas que visam a fins semelhantes, a princípio os fins da organização. Além do mais, esse discurso da cooperação procura conter, do ponto de vista prático, a inevitável catástrofe que seria caso os indivíduos fossem entregues à sorte de seus próprios interesses privados, pessoais. A individualidade e a competição em excesso poderiam destroçar o desempenho em grupo.

A metáfora que predomina dentro desse discurso da cooperação é a do esporte. $\mathrm{O}$ trabalho em equipe é visto como a melhor forma de desenvolver os talentos individuais. Contudo, esse trabalho em equipe funciona à base de uma depreciação cultural muito séria e profunda que segue em andamento: a depreciação da "dependência". O discurso da cooperação moderno opera jogando para baixo do tapete o fato de que seres humanos dependem uns dos outros para realizar seus propósitos. Ao inflar artificialmente e ilusoriamente o pronome "nós" do trabalho de equipe, o discurso da cooperação cria uma contradição subjetiva imensa: ao mesmo tempo em que incentiva a "cooperação", ele demoniza a dependência, celebrando a autonomia e a independência, porém autonomia e independência EM EQUIPE. As discussões sobre as redes de assistência atuais, sobre cooperação que não vise necessariamente a objetivos de organizações específicas, são vistas como "coisa de parasitas", que querem puxar para baixo a parcela de indivíduos vencedores e autônomos.

Por outro lado, o discurso da competição coexiste com o discurso da cooperação. Temos aqui uma subjetividade em constante conflito: ao mesmo tempo em que tem de se haver com trabalhos em equipe - com a cooperação - tem de se haver com o fato, duro e cruel, de que se não for esperto será passado para trás e será passado para trás pela equipe! É o tipo de equipe que só se forma quando há vitória. Não há passado, não há história; há arranjos momentâneos no "time" que vai jogar um certo jogo, aqui e agora. O discurso da competição, nesse sentido, não age neutralizando a cooperação, pois ambos fazem parte de uma mesma rede de crenças: a rede de crenças que coloca o modelo esportivo como metáfora da subjetividade "saudável", "bem realizada", "bem sucedida". Nesse modelo esportivo só importa a vitória. O discurso da concorrência, por incrível que pareça, é o motor, o tutano, do discurso da cooperação nas modernas configurações organizacionais de hoje, sobretudo das empresas "globalizadas", onde o espaço e o tempo - indispensáveis para a formação de 
redes de solidariedade e cooperação duradouras - são fugazes e rearranjáveis.

\section{Ponto 3: Subjetividade e trabalho redescritos}

No título desta mesa redonda está a expressão "classe trabalhadora". A princípio, essa expressão pode nos levar a pensar numa certa idéia de "homogeneidade". Os trabalhadores teriam, nessa visão equivocada, uma meta comum, interesses comuns e necessidades comuns. Na sociedade de classes do marxismo isso teria feito muito sentido. A "classe trabalhadora" era vista como um imenso corpo que exalava o mesmo cheiro e pedia a mesma coisa. No discurso de muitos sindicatos atuais isso não soaria ao todo estranho, embora a concepção geral quanto às particularidades de cada trabalho tenha mudado. Mas não creio ser nesse contexto que deveríamos falar em cooperação. Cooperação não implica apenas um conjunto de trabalhadores que se reúnem para chegar a uma meta idêntica para uma determinada categoria com objetivos iguais - identidades iguais ou coisa do tipo. Nem tampouco é a mesma coisa que a idéia moderna, típica do bê-á-bá do mercado de trabalho, de cooperação - aquela que vimos há pouco.

Em primeiro lugar, ao livrarmos nossa análise de conceitos essencialistas, como o conceito de que o trabalho é essencial para a formação da subjetividade, podemos começar a pensar num tipo de cooperação que não se resuma ao trabalho, mas que resgate o sentido positivo da dependência humana. Não haveria cooperação se não houvesse uma necessidade, se não houvesse o reconhecimento de que o ser humano depende de outros para sobreviver, tanto física quanto psicologicamente. A ligação social nasce, da forma mais elementar, do senso de mútua dependência. Cooperar não significa inflar o pronome "nós" e colocar sobre ele todos os "eus", formatando-os na ilusão de objetivos únicos e semelhantes - trabalhistas ou outros. Não tenho como fornecer uma concepção única do que seja a cooperação; isso iria variar de acordo com minhas preferências morais ou éticas e minhas experiências de vida. $O$ que pretendo mostrar é que o discurso da cooperação típico de nossos dias tende a trabalhar numa navalha incongruente: de um lado, a cooperação é incentivada, mas até o ponto em que não signifique dependência e tolhimento da iniciativa e autonomia individuais. Essa é a visão predominante.

Uma das características de nossa época é a produção de uma subjetividade vulnerável. Não é para menos, pois a cada dia que passa acreditamos menos na comunidade, achando que isso é coisa, ou das ONGs, ou das pessoas que não têm muito o que fazer. Curiosamente, a cooperação que ressalta esse aspecto comunitário, de redes de solidariedade e de continência mútua, tornou-se algo como um hobby, que inclusive está agora servindo como "aspecto de excelência" para candidatos a empregos. A cultura, a sociedade estão sendo repassados pelo discurso organizacional, esse em que até atividades comunitárias transformam-se em valor monetário. A cooperação, a solidariedade são, hoje, defensivas e não visam a conversações culturais mais profundas, à formação de um ambiente em que a diferença possa surgir e, a despeito de surgir, possa ser aceita como pura diferença num grupo, e não enquadrada em manuais sobre como "ir bem numa dinâmica de grupo" ou como "construir uma equipe de sucesso".

O desafio é romper o monólito que liga a solidariedade e a cooperação ao discurso sobre o trabalho [pelo menos no sentido de "mercado de trabalho". Ao rompê-lo talvez consigamos devolver certa positividade ao fato de que cooperação e dependência fazem interface uma com a outra. A cooperação pressupõe a presença do conflito e a disposição do outro para reconhecer-nos como um ser com o mesmo estatuto ético, independente de nossa posição no emprego. Se considerarmos que numa época como a nossa a "classe trabalhadora" 
dissolveu-se em muitas fagulhas, com distintos interesses e distintas dificuldades, talvez seja mais promissor encontrar outros pontos de ligação com o outro. Caso contrário, a competição, esta que desde a manhã até a noite encontramos em nossos leitos, vai continuar a ditar o que no passado já nos ditaram: "seja competitivo; afinal, esta é a essência verdadeira do ser humano".

\section{Cooperate to compete or compete to cooperate?}

This paper discusses competition and cooperation in the organizational setting, taking as a reference the conceptions of work and job that are going on in the current market place. The article assumes that work should be detached from all essentialistic characteristics that lie behind it, and that cooperation among people should not be constrained to work, but should embrace concepts as dependency and solidarity.

Keywords: competition, cooperation, meaning of work, pragmatism.

Endereço para contato com o autor: pedrofernando@terra.com.br 